\title{
Erratum to: Esophageal Adenocarcinoma Presenting as Pseudo-Achalasia in a Patient with Juvenile Polyposis Syndrome: An Enemy Out of the Blue
}

Carlene Lihalakha Chun - Saul Eisenstat •

Shane Dormady · Charles Lombard •

George Triadafilopoulos

Published online: 24 February 2011

(C) Springer Science+Business Media, LLC 2011

\section{Erratum to: Dig Dis Sci}

DOI 10.1007/s10620-011-1579-0
"Dysphagia" is spelled as "Dysphasia". Corrected figure is given below.

Figure 8 of the online published article was erroneously published with misspelled word. In Esophageal Dysphagia,

Fig. 8 Algorithm to consider when evaluating dysphagia.

* DES diffuse esophageal spasm

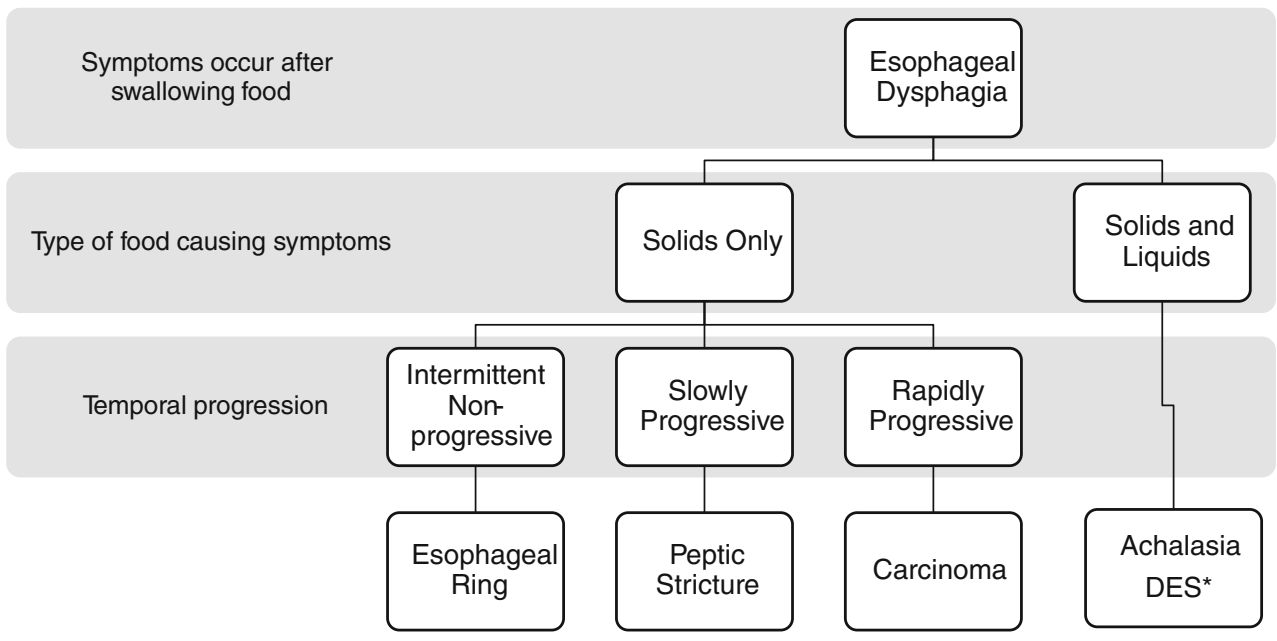

The online version of the original article can be found under doi:10.1007/s10620-011-1579-0.

\section{L. Chun $(\varangle) \cdot$ G. Triadafilopoulos}

Division of Gastroenterology and Hepatology, Stanford

University School of Medicine, Stanford, CA, USA

e-mail: carlene@stanford.edu

S. Eisenstat · S. Dormady - C. Lombard · G. Triadafilopoulos

El Camino Hospital, Mountain View, CA, USA 